\title{
Hubungan akomodasi insufisiensi dan astenopia pada remaja di Jakarta Barat
}

\author{
Nadia Fernanda ${ }^{1}$ Husnun Amalia ${ }^{2}$
}

\begin{abstract}
ABSTRAK
LATAR BELAKANG

Astenopia adalah gangguan pada indera penglihatan berupa ketidaknyamanan seperti gangguan membaca, sensitif terhadap cahaya, penglihatan kabur, diplopia dan distorsi persepsi. Salah satu etiologi astenopia adalah akomodasi insufisiensi. Penderita akomodasi insufisiensi tidak dapat mempertahankan akomodasi saat melihat dekat seperti membaca dan menulis. Hal ini akan mempengaruhi perkembangan akademisnya. Sehingga pada penelitian ini ingin diketahui hubungan akomodasi insufisiensi dan astenopia.

\section{METODE}

Penelitian merupakan studi cross sectional dengan desain analitik observasional. Pengumpulan data menggunakan kuesioner dilakukan pada 141 sampel yang didapatkan menggunakan consecutive sampling di sebuah Sekolah Menengah Atas di Jakarta Barat pada bulan Mei-Juni 2017. Pengukuran amplitudo akomodasi menggunakan Royal Air Force accommodation vergence measurement binocular Gauge. Analisis data menggunakan uji Fisher dengan tingkat kemaknaan $\mathrm{p}<0,05$.
\end{abstract}

\section{HASIL}

Prevalensi astenopia pada usia 15-17 tahun sebesar 83,7\% dengan sebagian besar etiologi yang belum diketahui. Prevalensi akomodasi insufisiensi sebesar 14,2\%. Pada usia tersebut ditemukan 54,2\% dengan amplitudo akomodasi 20D. Pada analisis dengan menggunakan uji Fisher menunjukkan tidak terdapat hubungan antara akomodasi insufisiensi dan astenopia $(\mathrm{p}=0,197)$.

\section{KESIMPULAN}

Tidak terdapat hubungan yang bermakna antara akomodasi insufisiensi dan astenopia pada remaja pertengahan.

Kata kunci : akomodasi insufisiensi, astenopia, remaja

\author{
${ }^{1}$ Program Studi Kedokteran, \\ Fakultas Kedokteran, \\ Universitas Trisakti \\ ${ }^{2}$ Departemen Ilmu Penyakit Mata, \\ Fakultas Kedokteran, \\ Universitas Trisakti

\section{Korespondensi:} \\ Husnun Amalia \\ Fakultas Kedokteran Universitas \\ Trisakti, Jalan Kyai Tapa No. 260, \\ Grogol, Jakarta Barat. \\ Email: husnun_a@trisakti.ac.id
}

\begin{abstract}
J Biomed Kes 2018;1(1):10-17
DOI: 10.18051/JBiomedKes.2018.

v1.10-17
\end{abstract}

pISSN: 2621-539X / eISSN: 2621-5470

Artikel akses terbuka (open access) ini didistribusikan di bawah lisensi Creative Commons Attribution 4.0 International (CC-BY 4.0) 


\section{ABSTRACT}

\section{Relation between accommodative insufficiency and asthenopia in adolescence on West Jakarta}

\section{BACKGROUND}

Asthenopia includes visual discomfort symptoms such as impaired reading performance, light sensitivity, blurred vision, diplopia, and perceptual distortions. One of the etiologies of asthenopia is accommodative insufficiency. Patients with accommodative insufficiency usually demonstrate poor accommodative sustaining ability in activities requiring near viewing such as reading and writing. This will affect child's academic progress. So in this study wanted to know relation between accommodative insufficiency and asthenopia.

\section{METHODS \\ This research used observational analytic study with cross-sectional design. On May-June 2017, data was collected throught questionnaires conducted in 141 sample that obtained using consecutive sampling in a Senior High School on West Jakarta. The examined amplitude of accommodation was measured using Royal Air Force accommodation vergence measurement binocular Gauge. Data analysis is perfomed by using Fisher test with a significance level of $\mathrm{p}<0.05$.}

\section{RESULT}

Out of 350 respondents, these study showed that 193 respondents $(55,1 \%)$ were depressed and 222 respondents (Prevalence of asthenopia at age $15-17$ was $83,7 \%$ with most of the etiology is unknown and $44.9 \%$ had risk factors for activities requiring near viewing. Prevalence of accomodative insufficiency was $14.2 \%$. At that age was found $54.2 \%$ with amplitude of accommodation $20 \mathrm{D}$. From the Fisher statistic test obtained significance level $\mathrm{p}=0.197$.

\section{CONCLUSION}

There is no significant relationship between accommodative insufficiency and asthenopia in adolescence.

Keywords : asthenopia, accommodative insufficiency, adolescence

\section{PENDAHULUAN}

Remaja (adolescence) adalah masa transisi atau peralihan dari masa kanak- kanak menjadi dewasa. Pada periode ini berbagai perubahan terjadi baik perubahan hormonal, fisik, psikologis maupun sosial. Perubahan psikososial pada remaja dibagi dalam tiga tahap yaitu remaja awal (early adolescent) usia 12-14 tahun, pertengahan (middle adolescent) usia 15-17 tahun, dan akhir (late adolescent) dimulai pada usia 18 tahun..$^{(1)}$

Astenopia adalah gangguan pada indera penglihatan berupa ketidaknyamanan seperti gangguan membaca, sensitif terhadap cahaya, penglihatan kabur, diplopia dan distorsi persepsi. ${ }^{(2)}$ Astenopia sering muncul pada aktivitas melihat dekat dimana memerlukan proses akomodasi dan vergence yang lebih intens seperti pada saat membaca dan menulis. ${ }^{(3)}$

Pada penelitian yang dilaksanakan oleh Vilela et $\mathrm{al}^{(3)}$ ditemukan prevalensi astenopia pada anak usia 6-16 tahun di Brazil Selatan, sebesar 24,7\% dari 964 anak. Penelitian lainnya yang dilaksanakan oleh Amalia $\mathrm{H}$ et $\mathrm{al}^{(4)}$ pada mahasiswa fakultas ilmu komputer ditemukan prevalensi astenopia sebesar $69,7 \%$ dari 99 mahasiswa. Pada penelitian tersebut akomodasi insufisiensi merupakan etiologi tertinggi yaitu $50,7 \%$.

Akomodasi insufisiensiadalah kelainan motor sensorik pada sistem penglihatan yang ditandai oleh ketidakmampuan mata untuk mempertahankan fokus pada saat melihat dekat. Secara klinis ditandai dengan adanya amplitudo akomodasi yang lebih rendah dari normal berdasarkan usia. ${ }^{(5)}$ Pasien dengan akomodasi insufisiensi biasanya mengalami kemampuan akomodasi yang kurang baik. ${ }^{(6)}$

Penelitian oleh Davis et $\mathrm{al}^{(7)}$ menggunakan subyek siswa sekolah Tohono O'odham, mendapatkan prevalensi terjadinya akomodasi insufisiensi sebesar $18,2 \%$ dari 484 subyek. Penelitian lainnya oleh Scheimann et $\mathrm{al}^{(8)}$ menggunakan subyek anak usia 9-17 tahun, mendapatkan prevalensi terjadinya penurunan amplitudo akomodasi berdasarkan usia sebesar 29\% dari 221 subyek.

Disfungsi akomodatif dan vergence dapat mempengaruhi perkembangan akademis anak atau kemampuan seseorang untuk berfungsi secara efisien dalam aktivitasnya. Bahkan ada anak yang melalaikan tugasnya 
karena ketidakmampuan mereka untuk mempertahankan akomodasi dan vergence dengan maksimal. ${ }^{(9)}$ Diharapkan dengan melakukan tatalaksana pada akomodasi insufisiensi, akan mengurangi gejala astenopia. $^{10}$

Berdasarkan penelitian di Indonesia sebelumnya didapatkan angka kejadian astenopia yang cukup tinggi yaitu mencapai $69,7 \% .{ }^{(4)}$ Vivela et $\mathrm{l}^{(3)}$ mendapatkan astenopia terjadi pada $24,7 \%$ pada anak usia 6-16 tahun, dan ditemukan $50,7 \%$ penderita astenopia disebabkan oleh akomodasi insufisiensi. ${ }^{(4)}$ Sehingga peneliti ingin meneliti lebih lanjut hubungan antara astenopia dan akomodasi insufisiensi yang nantinya dapat melakukan tindakan preventif agar akomodasi insufisiensi tidak mempengaruhi perkembangan akademis dan aktivitas remaja.

\section{METODE}

Penelitian ini menggunakan desain analitik observasional dengan pendekatan cross sectional. Penelitian dilaksanakan di sebuah SMA di Jakarta Barat, pada bulan MeiJuni 2017. Populasi pada penelitian ini adalah siswa kelas XI yang berjumlah 216 orang. Pemilihan sampel menggunakan metode consecutive sampling. Kriteria inklusi adalah siswa berusia 15-17 tahun. Sedangkan kriteria eksklusi adalah memiliki kelainan refraksi yang tidak terkoreksi.

Subyek penelitian yang memenuhi kriteria inklusi dan eksklusi diminta kesediaannya mengikuti penelitian melalui informed consent. Data dikumpulkan melalui wawancara menggunakan kuesioner astenopia yang berisi 15 pertanyaan mengenai astenopia. (4) Pengukuran amplitudo akomodasi (AA) dan akomodasi insufisiensi menggunakan Royal Air Force accommodation vergence measurement binocular Gauge. ${ }^{(11)}$ Pengukuran AA dilakukan dengan cara subyek diminta memfokuskan pada satu baris huruf. Secara perlahan gerakan obyek mendekati pasien dan minta subyek untuk memberitahu ketika huruf tampak kabur. Amplitudo akomodasi didapat dari titik tersebut. Metode ini disebut pushup method. ${ }^{(12)}$ Akomodasi insufisiensi adalah bila nilai amplitudo akomodasi lebih kecil dari nilai amplitudo akomodasi normal sesuai usianya menurut Donder's table. ${ }^{(5)}$

Metode yang digunakan adalah uji Fisher dengan tingkat kemaknaan $\mathrm{p}<0.05$ yang kemudian akan dianalisis menggunakan program SPSS (Statistical Package for Social Science) versi 23.0. Etika Penelitian didapatkan dari Komisi Etik Riset Fakultas Kedokteran Universitas Trisakti, Jakarta.

\section{HASIL}

\section{Analisa Univariat}

Analisa univariat digunakan untuk menilai distribusi karakteristik, prevalensi astenopia, frekuensi akomodasi insufisiensi sebagai etiologi astenopia, frekuensi amplitudo akomodasi.

Tabel 1. Distribusi karakteristik subyek $(n=141)$

\begin{tabular}{lll}
\hline \multirow{2}{*}{ Variabel } & \multicolumn{2}{l}{ Frekuensi } \\
\cline { 2 - 3 } & $\mathrm{n}$ & Persen (\%) \\
\hline Umur & 44 & 31,2 \\
15 tahun & 93 & 66 \\
16 tahun & 4 & 2,8 \\
17 tahun & & \\
Jenis Kelamin & & \\
Laki-laki & 65 & 46,1 \\
Perempuan & 76 & 53,9 \\
\hline
\end{tabular}

Berdasarkan tabel 1 didapatkan usia terbanyak pada penelitian ini adalah 16 tahun yaitu berjumlah 93 orang $(66 \%)$ dan jenis kelamin terbanyak adalah perempuan yaitu berjumlah 76 orang $(53,9 \%)$.

Tabel 2. Prevalensi astenopia dan akomodasi insufisiensi

\begin{tabular}{lll}
\hline \multirow{2}{*}{ Variabel } & \multicolumn{2}{l}{ Frekuensi } \\
\cline { 2 - 3 } & $\mathrm{n}$ & Persen (\%) \\
\hline Astenopia & 118 & $\mathbf{8 3 , 7}$ \\
Ya & 23 & 16,3 \\
Tidak & & \\
Akomodasi Insufisiensi & & \\
Ya & 20 & 14,2 \\
Tidak & 121 & $\mathbf{8 5 , 8}$ \\
\hline
\end{tabular}

Berdasarkan tabel 2 didapatkan $83,7 \%$ remaja mengalami astenopia dan $85,8 \%$ orang tidak mengalami akomodasi insufisiensi. 
Tabel 3. Distribusi frekuensi etiologi astenopia

\begin{tabular}{lll}
\hline \multirow{2}{*}{ Etiologi } & \multicolumn{2}{l}{ Frekuensi } \\
\cline { 2 - 3 } & $\mathrm{n}$ & Persen (\%) \\
\hline Kelainan rekraksi & 35 & 29,7 \\
Akomodasi insufisiensi & 6 & 5,1 \\
$\begin{array}{l}\text { Kelainan refraksi dan } \\
\text { akomodasi insufisiensi }\end{array}$ & 13 & 11 \\
Tidak diketahui & $\mathbf{6 4}$ & $\mathbf{5 4 , 2}$ \\
\hline Total & 118 & 100 \\
\hline
\end{tabular}

Berdasarkan tabel 3 etiologi astenopia sebagian besar tidak diketahui yaitu 54,2\%.

Tabel 4. Distribusi frekuensi amplitudo akomodasi

\begin{tabular}{lll}
\hline \multirow{2}{*}{ Amplitudo Akomodasi } & \multicolumn{2}{l}{ Frekuensi } \\
\cline { 2 - 3 } & Jumlah & Persen (\%) \\
\hline 3-5 dioptri & 7 & 5 \\
8-10 dioptri & 13 & 9,2 \\
12 dioptri & 10 & 7,1 \\
15 dioptri & 28 & 19,9 \\
20 dioptri & $\mathbf{8 3}$ & $\mathbf{5 8 , 9}$ \\
\hline Total & 141 & 100 \\
\hline
\end{tabular}

Berdasarkan tabel 4 ditemukan 58\% remaja memiliki amplitudo akomodasi 20 dioptri.

\section{Analisa Bivariat}

Analisa bivariat digunakan untuk menilai hubungan akomodasi insufisiensi dan astenopia. Berdasarkan tabel 5 analisis hubungan antara akomodasi insufisiensi dan astenopia dengan uji Fisher didapatkan $\mathrm{p}=0,197(\mathrm{p}>0,05)$ yang menunjukkan bahwa tidak adanya hubungan bermakna.

\section{PEMBAHASAN}

\section{Prevalensi astenopia}

Pada penelitian ini didapatkan jumlah subyek yang mengalami astenopia adalah 118 orang $(83,7 \%)$. Sedangkan penelitian yang dilakukan di Brazil oleh Vilela et al mendapatkan prevalensi astenopia pada anak usia 6-16 tahun sebesar 24,7\% dari 964 subyek. ${ }^{(3)}$ Penelitian yang dilakukan di Swedia oleh Abdi S mendapatkan jumlah penderita astenopia yang tertinggi dijumpai pada kelompok usia 14-16 tahun sebesar $26,7 \%$, dengan subyek penelitian adalah anak usia 6-16 tahun yang berjumlah 216 orang. Jumlah total subyek yang menderita astenopia pada penelitiannya adalah 50 orang $(23,1 \%)$. (13) Hal ini juga sesuai dengan penelitian yang dilakukan oleh Wajuihian SO yang mendapatkan penderita astenopia sebagian besar ditemukan pada siswa SMA. ${ }^{(14)}$

Angka kejadian astenopia yang didapatkan dalam penelitian kami menunjukkan nilai yang jauh lebih besar, hal ini dapat disebabkan oleh rentang usia yang digunakan oleh penelitian-penelitian sebelumnya lebih luas yaitu 6-16 tahun. Tingginya jumlah penderita astenopia pada siswa SMA dapat disebabkan oleh meningkatnya kegiatan belajar sehingga mereka akan menghabiskan waktu yang lebih banyak untuk berkonsentrasi saat belajar. Hal ini akan menyebabkan terjadinya akomodasi yang lebih lama karena adanya aktifitas membaca dan menulis. Sehingga menimbulkan gejala astenopia yang berhubungan langsung dengan akomodasi saat membaca dan menulis. ${ }^{(3)}$

\section{Prevalensi akomodasi insufisiensi}

Akomodasi insufisiensi adalah salah satu bentuk dari disfungsi akomodasi. (6) Kelainan ini ditandai dengan adanya ketidakmampuan mata untuk mempertahankan fokus pada saat melihat dekat. Diagnosis akomodasi insufisiensi dapat ditegakkan apabila nilai amplitudo akomodasi lebih rendah dari usia yang seharusnya

Tabel 5. Hubungan akomodasi insufisiensi dan astenopia $(n=141)$

\begin{tabular}{|c|c|c|c|c|c|c|c|c|}
\hline \multirow{3}{*}{ Variabel } & & \multicolumn{4}{|c|}{ Astenopia } & \multirow{2}{*}{\multicolumn{2}{|c|}{ Total }} & \multirow{3}{*}{ Nilai $p$} \\
\hline & & \multicolumn{2}{|l|}{$\mathrm{Ya}$} & \multicolumn{2}{|c|}{ Tidak } & & & \\
\hline & & $\mathrm{n}$ & $\%$ & $\mathrm{n}$ & $\%$ & $\mathrm{n}$ & $\%$ & \\
\hline \multirow[t]{2}{*}{ Akomodasi Insufisiensi } & Ya & 19 & 13,5 & 1 & 0,7 & 20 & 14,2 & \multirow[b]{2}{*}{$0,197 *$} \\
\hline & Tidak & 99 & 70,2 & 22 & 15,6 & 121 & 85,8 & \\
\hline Total & & 118 & 83,7 & 23 & 16,3 & 141 & 100 & \\
\hline
\end{tabular}

* uji Fisher 
berdasarkan Donder's table. ${ }^{(5)}$ Pada usia 1517 tahun didiagnosis mengalami akomodasi insufisiensi jika nilai amplitudo akomodasi $\leq 10$ dioptri. Pada penelitian ini terdapat 20 orang $(14,2 \%)$ yang mengalami akomodasi insufisiensi dari 141 subyek. Penelitian oleh Scheimann didapatkan penurunan amplitudo akomodasi sebesar 29\% dari 221 subyek usia 9-17 tahun. ${ }^{(8)}$ Pada penelitian ini didapatkan hasil $14,2 \%$ yang menunjukkan nilai yang lebih kecil dibandingkan dengan penelitian oleh Scheimann yaitu 29\%. Hal ini dapat disebabkan oleh adanya perbedaan rentang usia subyek penelitian. Penelitian yang kami lakukan menggunakan subyek berusia 15-17 tahun sedangkan Scheimann ${ }^{(8)}$ menggunakan subyek yang rentang usianya lebih luas yaitu berusia 9-17 tahun.

Pada subyek yang menderita akomodasi insufisiensi dapat diberikan penatalaksanaan dengan diberikan lensa sferis positif $(+1.00$ D). Latihan dengan menggunakan lensa ini dapat dilakukan selama 8-12 minggu. (13) Setelah terapi penderita umumnya menunjukkan pengurangan gejala. ${ }^{(15)}$ Saat ini dapat juga diberikan tatalaksana dengan menggunakan vision therapy. ${ }^{(6)}$

\section{Etiologi astenopia}

Etiologi astenopia dibagi menjadi astenopia refraktif (miopia, hipermetropia, astigmatisma dan anisometropia) dan astenopia muskular (heterotropia atau heteroforia, konvergen insufisiensi dan akomodasi insufisiensi). Pada penelitian ini etiologi yang diteliti adalah kelainan refraksi dan akomodasi insufisiensi. Dimana mendapatkan hasil penyebab astenopia yang tidak diketahui sebesar 54,2\%, kelainan refraksi sebesar 29,7\%, akomodasi insufisiensi sebesar 5,1\% dan keduanya sebesar $11 \%$. Penelitian yang dilakukan oleh Abdi $\mathrm{S}^{(13)}$ mendapatkan hasil kelainan refraksi yaitu miopia dan astigmatisma merupakan penyebab terbanyak pada kejadian astenopia. Penelitian yang dilakukan oleh Wajuihian ${ }^{(14)}$ mendapatkan hasil yang sama, yaitu astigmatisma merupakan penyebab terbanyak dari astenopia. Namun, pada penelitian ini tidak dijelaskan jenis kelainan refraksi yang ditemukan.

Penelitian kami mendapatkan hasil penyebab astenopia yang paling tinggi $(54,2 \%)$ adalah tidak diketahui penyebabnya. Sedangkan etiologi astenopia lainnya yang tidak diteliti dalam penelitian ini adalah heterotropia atau heteroforia dan konvergen insufisiensi.

\section{Amplitudo akomodasi}

Berdasarkan Donder's table, penilaian amplitudo akomodasi dilakukan berdasarkan usia. Nilai normal amplitudo akomodasi pada usia 15-17 tahun adalah $\geq 12$ dioptri. $^{(16)}$ Pada penelitian ini ditemukan terdapat nilai amplitudo akomodasi yang lebih rendah berdasarkan usia dengan nilai 3-5 dioptri adalah berjumlah 7 orang (5\%) dan 13 orang $(19,2 \%)$ yang memiliki nilai 8-10 dioptri. Sedangkan nilai amplitudo akomodasi normal berdasarkan usia dengan nilai 12 dioptri berjumlah 10 orang $(7,1 \%)$, nilai 15 dioptri berjumlah 28 orang $(19,9 \%)$ dan 20 dioptri berjumlah 83 orang $(58,9 \%)$.

Pada penelitian yang dilakukan Ovenseri-Ogbomo $\mathrm{G}$, et al didapatkan nilai amplitudo akomodasi sebesar 16,86 \pm SD 3,07 pada 435 subyek. ${ }^{(17)}$ Pada penelitian tersebut memperlihatkan hasil nilai amplitudo akomodasi seluruh subyek adalah normal. Hal ini menunjukkan hasil yang berbeda dengan penelitian ini yaitu nilai amplitudo akomodasi normal sebesar $85,8 \%$ dan dibawah normal sebesar 14,2\%. Perbedaan tersebut dapat disebabkan oleh pada penelitian sebelumnya menggunakan rumus Hofstetter, sedangkan pada penelitian ini menggunakan Donder's table.

\section{Hubungan akomodasi insufisiensi dan astenopia}

Pada penelitian ini didapatkan penderita astenopia berjumlah 118 orang $(83,7 \%)$ dari 141 orang. Subyek yang memiliki akomodasi insufisiensi berjumlah 20 orang $(14,2 \%)$ dari 141 orang penderita astenopia. Sedangkan yang memiliki akomodasi insufisiensi dan astenopia berjumlah 19 orang $(13,5 \%)$. Terdapat hal yang sangat menarik pada penelitian ini. Jumlah penderita 
akomodasi insufisiensi adalah 20 orang dan 19 orang diantaranya menderita astenopia, yaitu mencapai $95 \%$ penderita akomodasi insufisiensi mengalami astenopia. Sehingga penderita akomodasi insufisiensi hampir seluruhnya akan mengalami astenopia. Namun ternyata akomodasi insufisiensi bukan menjadi penyebab tertinggi dalam menimbulkan astenopia pada kelompok umur 15-17 ini.

Hasil analisis hubungan akomodasi insufisiensi dan astenopia dengan menggunakan uji Fisher menunjukkan hasil $\mathrm{p}=0,197 \quad(\mathrm{p}>0,05) \quad$ sehingga dapat diambil kesimpulan bahwa tidak terdapat hubungan antara akomodasi insufisiensi dan astenopia pada remaja.

Penelitian yang dilakukan oleh Amalia $\mathrm{H}$, et $\mathrm{al}^{(4)}$ menggunakan subyek 99 mahasiswa Fakultas Ilmu Komputer Universitas Indonesia ditemukan 69 orang $(69,7 \%)$ yang mengalami astenopia. Etiologi tertinggi merupakan akomodasi insufisiensi yaitu berjumlah 35 orang (50,7\%). Sedangkan etiologi tertinggi yang didapatkan dalam penelitian ini adalah tidak diketahui sebesar $(54,2 \%)$, disusul dengan kelainan refraksi sebesar $(29,7 \%)$ dan akomodasi isnufisiensi hanya didapatkan sebanyak 6 orang $(5,1 \%)$ dari total keseluruhan subyek penderita astenopia. Penelitian kami menunjukkan etiologi akomodasi insufisiensi yang lebih rendah dalam menyebabkan astenopia.

Hal ini dapat disebabkan karena adanya perbedaan usia dan aktivitas subyek. Pada penelitian sebelumnya subyek yang diteliti berusia 18-26 tahun dan sebesar 75\% menggunakan komputer dengan durasi 3-4 jam/hari. Sedangkan pada penelitian ini subyek berusia 15-17 tahun dengan aktivitas melihat dekat sebesar 53\%. Terdapat juga perbedaan etiologi astenopia yang diteliti dalam penelitian ini.

Penelitian yang dilakukan oleh Amalia $\mathrm{H}$, et al etiologi dibagi berdasarkan etiologi tipe refraktif (miopia, astigmatisma, konvergen insufisiensi dan akomodasi insufisiensi) dan etiologi tipe muskular (heteroforia, intermitern heteroforia dan konvergen insufisiensi). ${ }^{(4)}$ Sedangkan pada penelitian ini etiologi yang diteliti adalah kelainan refraksi, akomodasi insufisiensi, penyebab yang tidak diketahui dan konsumsi obat-obatan.

Pada umumnya anak usia sekolah mengalami astenopia selama melakukan aktivitas yang berkaitan dengan membaca dan menulis. ${ }^{(15,18)}$ Gejala yang muncul dapat berupa sakit kepala, rasa tidak nyaman pada mata dan mata merah, pandangan kabur, kesulitan mempertahankan fokus pada satu obyek dan diplopia. ${ }^{(15)}$ Astenopia dapat menimbulkan masalah pada saat membaca, menulis, atensi, memori, serta proses pembelajaran disekolah. $(19,20)$

\section{KESIMPULAN}

Berdasarkan hasil dari penelitian yang sudah dilaksanakan maka dapat ditarik beberapa kesimpulan seperti berikut:

- Prevalensi astenopia pada remaja pertengahan sebesar $83,7 \%$

- Prevalensi akomodasi insufisiensi pada remaja pertengahan sebesar $14,2 \%$

- Etiologi astenopia pada remaja pertengahan terbanyak adalah tidak diketahui yaitu sebesar $54,2 \%$

- Nilai amplitudo akomodasi pada remaja pertengahan yang paling banyak ditemukan adalah 20 D yaitu $58,9 \%$

- Tidak terdapat hubungan antara akomodasi insufisiensi dan astenopia pada remaja pertengahan $(p=0,197)$

\section{SARAN}

Untuk penelitian selanjutnya, disarankan untuk meneliti lebih lanjut mengenai etiologi lainnya yang berperan dalam kejadian timbulnya astenopia antara lain kelainan refraksi, heterophoria atau heterotropia dan konvergen insufisiensi. Sebaiknya penelitian dilakukan dengan jumlah sampel yang lebih banyak dan karakteristik yang lebih heterogen

\section{UCAPAN TERIMA KASIH}

Dalam penyusunan dan penulisan skripsi ini tidak terlepas dari bantuan, 
bimbingan serta dukungan dari berbagai pihak. Oleh karena itu dalam kesempatan ini penulis menyampaikan terima kasih kepada dr. Suriptiastuti, DAP\&E, MS selaku Dekan, dr. Hannah, Sp.A, M.Kes, dr. Meiriani Sari, Sp.A, MSc, IBCLC dan dr. Nathalia Ningrum, Sp.A selaku penguji yang telah memberikan banyak masukan dalam menyempurnakan penelitian ini. Kedua orang tua penulis, Kepala sekolah dan staf pengajar SMAN 23 Jakarta Barat, dan semua pihak yang tidak dapat disebutkan satu persatu yang telah banyak membantu penelitian ini.

\section{DAFTAR REFERENSI}

1. Batubara JRL. Adolescent Development (Perkembangan Remaja). Sari Pediatri. 2010;12(1):21-9

2. Han CC, Liu R, Liu RR, etal. Prevalence of Asthenopia and Its Risk Factors in Chinese College Students. Int J Ophthalmol. 2013;6(5):718-22. DOI: $10.3980 / \mathrm{j}$. issn.2222-3959.2013.05.31

3. Vilela MAP, Castagno VD, Meucci RD, Fassa AG. Asthenopia in Schoolchildren. Clinical Ophthalmology. 2015;9:1595603.http://dx.doi.org/10.2147/OPTH. S84976

4. Amalia H, Suardana GG, Artini W. Accommodative Insufficiency As Cause of Asthenopia in Computer-using Students. Univ Med. 2010;29:78- 83

5. Marran LF, De Land PN, Nguyen AL. Accommodative Insufficiency is The Primary Source of Symptoms in Children Diagnosed with Convergence Insufficiency. Optometry and Vision Science. 2006;83:E281-E289. DOI:10.1097/01. opx.0000216097.78951.7b.

6. Cooper JS, Burns CR, Cotter SA, et al. Optometric Clinical Practice Guideline Care of The Patient with Accommodative and Vergence Dysfunction. $3^{\text {rd }}$ ed. St. Louis. American Optometric Association. 2011

7. Davis AL, Harvey EM, Twelker JD, et al. Convergence Insufficiency, Accommodative Insufficiency, Visual
Symptoms and Astigmatism in Tohono O'odham Students. Journal of Ophthalmology.2016;2016:1-7.http:// dx.doi.org/10.1155/2016/6963976

8. Scheimann M, Cotter S, Kulp MT, et al. Treatment of Accommodative Dysfunction in Children: Results from an Random Clinical Trial. Optom Vis Sci. 2011;88(11):1343-52. Doi:10.1097/ OPX.0b013e31822f4d7c.

9. Garcia-Munoz A, Carbonell-Bonete, Cacho-Martinez P. Symptomatology Associated with Accommodative and Binocular Vision Anomalies. Journal of Optometry 2014;7:178-92. http://dx.doi. org/10.1016/j.optom.2014.06.005

10. Iwasaki $T$, Nagata $T$, Tawara $A$. Potential Preventive Effects of A New Visual Intervention for Accommodative Insufficiency and Asthenopia Due to Sustained Near Task. Ophthalmologica. 2012;228(3):181-7. DOI: $10.1159 / 000334621$

11. Ophthalmic Instruments: Keeler 2301-L1020 RAF Binocular Guage. Available at http://www.ophthalmic.com.my/ Keeler-2301-L-1020-RAF-BinocularGuage/q?pid $=206 \&$ doit $=$ order $\quad$ Accesed November, 252016

12. Keirl A, Christie C. Clinical Optics and Refraction: A Guide for Optometrists, Contact Lens Opticians and Dispensing Opticians. $1^{\text {st }}$ ed. Philadelphia: Elsevier Ltd; 2007

13. Abdi S. Asthenopia in Schoolchildren. $1^{\text {st }}$ Ed. Stockholm: Karolinska University Press; 2007

14. Wajuihian SO. Frequency of Asthenopia and Its Association with Refractive Errors. Afr Vision Eye Health. 2015;74:17. DOI:https://doi.org/10.4102/aveh. v74i1.293

15. Abdi S, Brautaset R, Rydberg A, et al. The Influence of Accommodative Insufficiency on Reading. Clin Exp Optom. 2007;90(1):36-43. DOI: https://doi.org/10.1111/j.14440938.2006.00090.x

16. Carlson NB, Kurz D. Clinical Procedures for Ocular Examination. $3^{\text {rd }}$ ed. New 
York: Mc Graw-Hill; 2004

17. Ovenseri-ogbomo GO, Kudjawu EP, Kio FE, et al. Investigation of Amplitude of Accommodation Among Ghanaian School Children. Clin Exp Optom. 2012;95:187-91. https://doi.org/10.1111/ j.1444-0938.2011.00692.x

18. Gupta R, Sharma B, Anand R, et al. Association of Asthenopia and Covergence Insufficiency in Children with Refractive Error-A hospital based study.Int J Med Res Rev. 2013;1(5):2227. Doi:10.17511/ijmrr.2013.i05.002.

19. Vilela MA, Pellanda LC, Fassa AG, et al. Prevalence of Asthenopia in Children: A Systematic Review with Metaanalysis. J Pediatr (Rio J). 2015;91:3205. DOI:https://doi.org/10.1016/j. jped.2014.10.008

20. Cohen Y, Segal O, Barkana Y, et al. Correlation between athenopic symptoms and different measurements of convergence and reading comprehension and saccadic fixation eye movement. Optometry.2010;81:28-34.doi:10.1016/j. optm.2008.10.019 